\title{
Pulmonary cytomegalic inclusion-body disease in a diabetic
}

\author{
BRIAN E. HEARD, A. M. HASSAN, AND STEPHANIE M. WILSON \\ From the Department of Pathology, Postgraduate Medical School of London
}

SYNOPSIS Cytomegalic inclusion-body disease was found at necropsy in the lungs of a 57-year-old diabetic man. The characteristic large cells were found in all parts of the lungs. The alveolar walls showed no cellular infiltration, supporting Hamperl's suggestion that the cytomegalic virus alone may be incapable of causing pneumonitis. A small focus of aspergillosis was also found in one lung.

The rarity of cytomegalic inclusion-body disease in adults was confirmed by re-examining histologically the lungs of 15 further cases of diabetes as well as 60 of other chronic diseases. No further example of pulmonary cytomegaly was found.

In a recent account of three cases of generalized cytomegalic inclusion-body disease, Symmers (1960) pointed out that in adults it is usually a complication of some other disease or its treatment. Hamperl (1956) found no evidence that cytomegalic virus alone was capable of causing pneumonitis in adults.

The views of these authors are supported by the subject of the present communication. Pulmonary cytomegalic inclusion-body disease occurred in the present case as a complication of diabetes with Kimmelstiel-Wilson nephritis. Although the characteristic cells were found in all blocks from both lungs, no pneumonitis in the form of a cellular infiltrate of alveolar walls could be found nor Pneumocystis carinii.

In order to determine whether we had overlooked other cases, we re-examined lung sections from 75 other necropsies on patients dying from other chronic illnesses, including 15 with KimmelstielWilson nephritis, for cytomegaly. No further examples were found.

\section{CASE HISTORY AND CLINICAL FINDINGS}

An electrician was discharged from the Royal Navy at the age of $\mathbf{4 4}$ years with glycosuria. He was given a low carbohydrate diet, but gradually developed thirst, tiredness, weight loss, cramps, and dyspnoea. At the age of 56 years he attended Hammersmith Hospital Diabetic Clinic under Professor T. Russell Fraser.

On examination he was obese and weighed $168 \frac{1}{2} \mathrm{lb}$. His blood pressure was $160 / 90 \mathrm{~mm} . \mathrm{Hg}$. His fasting blood sugar was $214 \mathrm{mg}$. \% and there was glycosuria and occasional proteinuria. No sign of ketosis was found and he was given a reducing diet, as a result of which he lost $14 \frac{1}{2} \mathrm{lb}$. and most of the glycosuria.

He was admitted to Hammersmith Hospital two months before death, at the age of 57 , with a history of recent 'influenza' and urinary frequency and swelling of the ankles for one week. He had not been short of breath over the past year, but had had a cough with mucoid sputum for six months. There was oedema of the legs and sacrum, the blood pressure was now raised to 220/110 $\mathrm{mm} . \mathrm{Hg}$, and he had an apical systolic murmur. There was oliguria $(150 \mathrm{ml} . / 24 \mathrm{hr}$.) and the urine showed occasional casts, no red cells, and 2 to $4 \mathrm{~g}$. of protein a day. Kimmelstiel-Wilson nephritis was diagnosed and this was confirmed by a renal biopsy.

He was maintained on a low-protein diet, chlorthiazide and potassium chloride but the blood urea did not fall and oedema returned.

Three weeks before death prednisone was started (60 mg./day), along with insulin, but he continued to deteriorate with oedema, ascites, and right hydrothorax. Ten days before death crepitations were noted at the right base and the sputum was purulent. The chest radiograph showed marked elevation of the diaphragm with pleural reaction in both costophrenic angles and some localized shadowing on both sides posteriorly. Terminally he was thought to have bronchopneumonia, he became very drowsy and died after long periods of apnoea.

The cause of death was diabetes mellitus with obesity, Kimmelstiel-Wilson nephritis, and uraemia.

\section{NECROPSY FINDINGS}

The body (weight $171 \mathrm{lb}$., height $5 \mathrm{ft}$. $10 \mathrm{in}$.) showed oedema of the legs, sacral area, and scrotum, and the abdomen was distended by ascites (4 litres). 
The trachea and main bronchi were congested and contained a large amount of frothy mucus. The right pleura contained about $100 \mathrm{ml}$. of turbid yellow fluid and the left contained $200 \mathrm{ml}$. of thicker yellow fluid. The right lung weighed $1,040 \mathrm{~g}$. The external surface was free of adhesions. The transverse fissure was incomplete anteriorly but the oblique fissure was normal. There was moderate dust pigmentation in most parts, accompanied by numerous small blebs with pale centres, and this was striped on the lateral surface of the lower lobe. The hilar glands were small and pigmented. There was gross pulmonary oedema and fluid poured from the cut surface. In the anterior segment of the upper lobe, $1.5 \mathrm{~cm}$. deep to the pleura, was a pale yellow focus of consolidation, $1.5 \mathrm{~cm}$. maximum diameter. Two smaller pale foci, 0.2 and $0.4 \mathrm{~cm}$., were found anteriorly, the larger lying near the centre of the surface facing the middle lobe. Near the centre of the diaphragmatic surface was a small focus of collapse, $2 \mathrm{~cm}$. across, with a slight bronchiectasis. There was no suggestion of bronchopneumonia. The segmental bronchi were congested but normal in diameter and thickness. Scattered through the lung were numerous, small, dust-pigmented foci with slightly dilated bronchioles - mild centrilobular emphysema.

The left lung $(985 \mathrm{~g}$.) showed a fibrinous exudate over the apical segment. There were dust pigment stripes on the lateral surface of the upper lobe but elsewhere pigmentation was minimal. Pigmentation was accompanied by minute blebs with fibrous centres. Part of the apical segment of the upper lobe was consolidated, $5 \mathrm{~cm}$. diameter, firmer than the rest of the lung and pale in parts. The rest of the lung was very oedematous but no more pale foci were found. This lung also showed mild centrilobular emphysema. The bronchi were inflamed but normal in calibre and thickness.

The heart ( $370 \mathrm{~g}$.) showed slight hypertrophy of the right ventricle $(5 \mathrm{~mm}$. in the outflow pathway) but no other features. The stomach showed two small erosions. The kidneys were enlarged (right 207 g. and left 213 g.) and showed numerous petechiae. There was an adenoma of the right adrenal. All other organs were normal.

\section{HISTOLOGICAL FINDINGS}

Numerous blocks were taken from both lungs for histological examination and all showed evidence of cytomegalic inclusion-body disease. The characteristic large cells (Fig. 1) measured up to $30 \mu$ in diameter and contained nuclear inclusions up to $10 \mu$ in diameter. In addition, some large cells contained a number of cytoplasmic inclusions up to $2 \mu$ in diameter (Fig. 2).
The large cells were mostly in alveoli, either lying free in the lumen or attached to alveolar walls. In individual sections they were often distributed irregularly so that eight or more might be seen in one high-power field and none in another. Occasionally they were in clumps.

The nuclear inclusions were pink or blue in sections stained with haematoxylin and eosin. They were round, oval, or slightly lobulated and the edge was feathery. They failed to stain with periodicacid-Schiff reaction and Sudan black. They stained faintly with Best's carmine stain for glycogen and negatively or faintly with a Feulgen reaction. There was frequently a clear zone inside the nuclear membrane and this was sometimes crossed by fine strands resembling prickles of the epidermis and appearing to originate in the inclusion. There was an occasional orbital body (Fig. 1). The peripheral nuclear chromatin was made prominent by the subjacent clear zone.

The cytoplasm of the large cells was plentiful, had a sharp rounded edge, and stained bluish-pink with haematoxylin and eosin. Dust pigment or haemosiderin were occasionally present but the most striking inclusions in the cytoplasm were roughly spherical bodies up to $2 \mu$ in diameter. They were usually collected to one side of the nucleus and strongly stained by the periodic-acid-Schiff reaction (Fig. 2). They also showed a positive Feulgen reaction but failed to take up Sudan black or Best's carmine.

On the surface of the apical segment of the left upper lobe was a fibrinous deposit with early organization and the underlying lung was infarcted. Incidentally, the pleural mesothelium was sometimes cubical but never showed cytomegaly.

One of the small pale foci $(0.4 \mathrm{~cm}$. across) in the anterior segment of the right upper lobe contained hyphae of a fungus, probably Aspergillus fumigatus, lying in an abscess showing occasional giant cells (with numerous peripheral nuclei) besides fibrin and many neutrophils. No fungus was found in the other pale areas in the right upper lobe or elsewhere in the lungs. There was slight carnification at the right base.

Collections of unaffected macrophages were plentiful in all lung sections. Where iron or dust pigment obscured the nuclei they could have been cytomegalic, especially as some contained P.A.S.positive granules in the cytoplasm.

Bronchi were examined for epithelial cytomegaly but none was found. The mucosa was slightly inflamed. Bronchial glands were normal. A few large cells were found free in the lumen of the left postero-apical bronchus, presumably derived from more distal airways. 


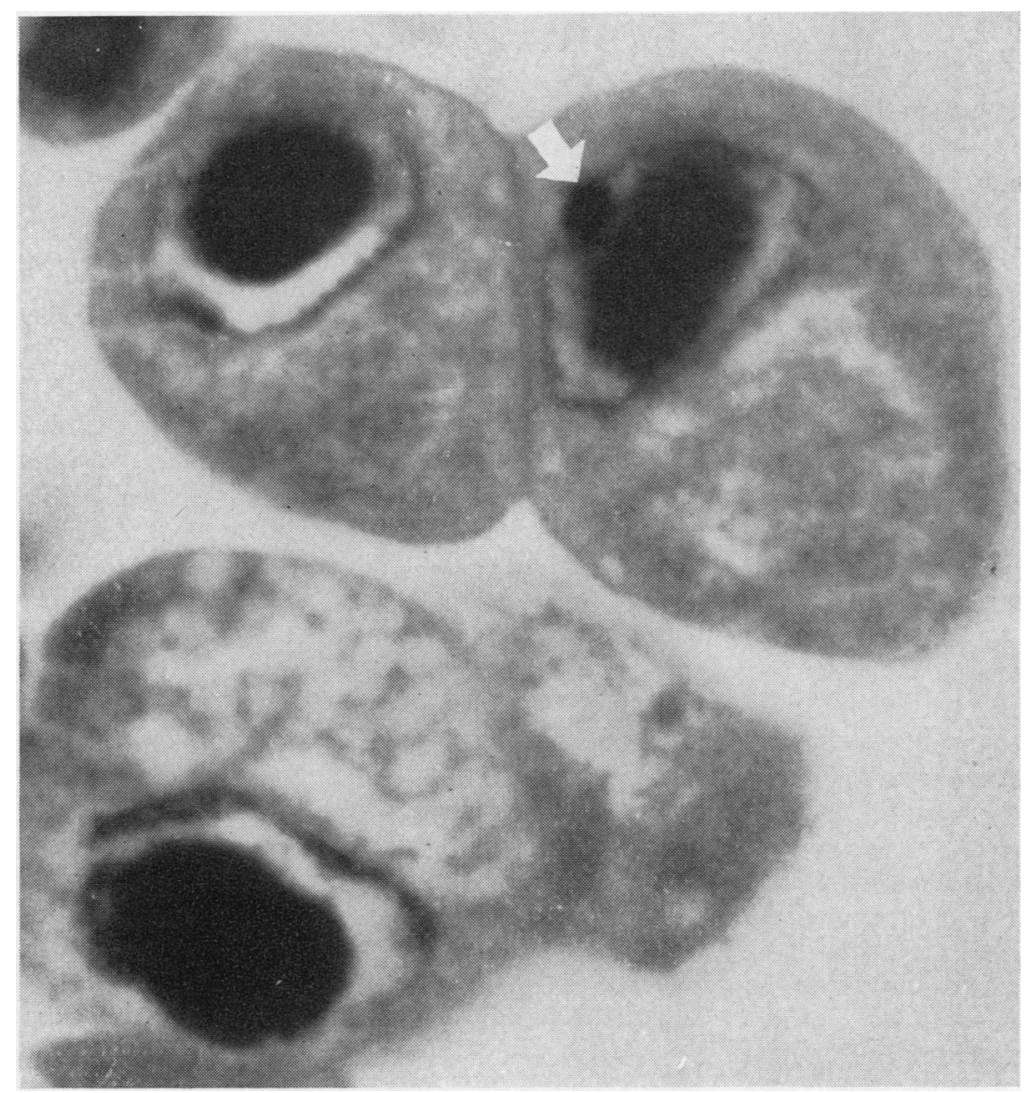

FIG. 2

FIG. 1. Part of a group of eight characteristic cells lying free in an alveolus. The nuclear inclusion with a hazy peripheral zone is surrounded by a clear zone between it and the nuclear membrane. The cell on the right shows an 'orbital body' (arrow) on the nuclear membrane. The cytoplasm is finely vacuolated or granular. (Haematoxylin and eosin $\times$ 2,640 ).

FIG. 2. Two large cells with prominent cytoplasmic inclusions stained by the periodicacid-Schiff reaction. The nuclear inclusion in the lower cell is not stained $(\times 2,640)$. 
Hilar lymph nodes were searched for large cells without success.

The kidneys showed typical glomerular nodules of Kimmelstiel-Wilson nephritis; the islets of the pancreas appeared normal. These and other organs (heart, spleen, liver, stomach, thyroid, and adrenals) were free of inclusion bodies.

To confirm that cytomegalic inclusion-body disease is rare in the lungs and not a neglected diagnosis, lung sections from 15 cases of Kimmelstiel-Wilson disease coming to necropsy and 60 cases of other chronic illness (15 each of uraemia, anaemia, chronic leukaemia, and Hodgkin's disease) were re-examined carefully for inclusions. No further sample was encountered.

\section{DISCUSSION}

Cytomegalic inclusion-body disease has been reviewed recently by Nelson and Wyatt (1959). Although it has been known to occur in children since 1904 (Jesioneck and Kiolemenoglou) the first adult case was not published until 1925 (von Glahn and Pappenheimer). Symmers (1960) collected 34 adult cases from the literature. He noted that in 19 the disease was probably localized to one organ, as in the present case.

In the present case all blocks from both lungs showed the characteristic large cells but there was no evidence of concomitant pneumonitis in the form of cellular infiltration of the alveolar walls. As a result of his findings in a similar case, Hamperl (1956) suggested that the cytomegalic virus alone may be incapable of causing pneumonitis. He found pneumonitis when Pneumocystis infection accompanied cytomegaly. In another case of a 32-year-old man who died of a sarcomatous type of Hodgkin's disease, he failed to find pneumonitis in an area where numerous cytomegalic cells in alveoli were bordering on pulmonary infiltration by tumour. Wyatt, Hemsath, and Soash (1951) found the disease in a 20-year-old woman with primary refractive anaemia and reported that apart from the cells with inclusions, the rest of the lung was free of pathological change. In one of the cases reported by Reinhard, Good, and Martin (1950), Dr. Lauren V. Ackerman described focal collections of giant cells with large intranuclear acidophilic inclusions but no pneumonitis was described. Incidentally he thought it doubtful whether the presence of this virus had anything to do with the patient's death from lymphocytic leukaemia.

Fungus infections are well known in diabetics. Gukelberger (1938) reported a diabetic with pulmonary mucormycosis and Gregory, Golden, and Haymaker (1943) described three diabetics with mucormycosis of the central nervous system. In the present case, a decreased resistance to infection would account for both the aspergillosis and for the cytomegaly. Recent work suggests that the decreased resistance in such chronic illnesses as multiple myelomatosis and lymphocytic leukaemia may be due to hypogammaglobulinaemia. Hutchison (1955) described two patients with primary hypogammaglobulinaemia dying of pneumonia due to Pneumocystis carinii. This factor is not applicable in the present case, however, as the globulins were raised.

We wish to thank Professor C. V. Harrison for his advice, Professor T. Russell Fraser for permission to publish the clinical findings, and Mr. W. Brackenbury for the photomicrographs.

\section{REFERENCES}

Glahn, W. C. von, and Pappenheimer, A. M. (1925). Amer. J. Path. $1,445$.

Gregory, J. E., Golden, A., and Haymaker, W. (1943). Johns Hopk. Hosp. Bull., 73, 405.

Gukelberger, M. (1938). Dtsch. Arch. klin. Med., 182, 28.

Hamperl, H. (1956). Amer. J. Path., 32, 1.

Hutchison, J. H. (1955). Lancet, 2, 844, 1196.

Jesioneck, A., and Kiolemenoglou, B. (1904). Münch. med. Wschr. $51,1905$.

Nelson, J. S., and Wyatt, J. P. (1959). Medicine (Baltimore), 38, 223.

Reinhard, E. H., Good, J. T., and Martin, E. (1950). J. Amer. med. Ass., 142, 383.

Symmers, W. St. C. (1960). J. clin. Path., 13, 1.

Wyatt, J. P., Hemsath, F. A., and Soash, M. D. (1951). Amer. J. clin. Path., 21, 50. 